\title{
Acute Upper Gastrointestinal Bleeding in Hexagenerians or Older ( $\geqslant 60$ Years) Versus Younger (<60 Years) Patients: Clinico-Endoscopic Profile and Outcome
}

\author{
Rajpal S. Yadav ${ }^{1}$, Payal Bargujar ${ }^{2}$, Hans R. Pahadiya ${ }^{3}$, Rahul K. Yadav ${ }^{4}$, Jitendra Upadhyay ${ }^{4}$, Alok Gupta \\ ${ }^{1}$, Manoj Lakhotia ${ }^{1}$ \\ 1. Internal Medicine, Dr. Sampurnanand Medical College, Jodhpur, IND 2. Pediatrics, Sawai Man Singh Medical \\ College, Jaipur, IND 3. Medicine, Sawai Man Singh Hospital, Jaipur, IND 4. Medicine, Sawai Man Singh Medical College, \\ Jaipur, IND
}

Corresponding author: Hans R. Pahadiya, drhans05sms@gmail.com

\section{Abstract}

\section{Background and aims}

Acute upper gastrointestinal (UGI) bleeding is one of the serious and potentially life-threatening medical emergencies, causing significant mortality and morbidity. This study aimed to evaluate the clinicoendoscopic profile and outcome among patients aged $<60$ years who presented for UGI bleeding compared to those aged $\geqslant 60$ years.

\section{Methods}

This prospective observational study was conducted among 194 patients who presented with symptoms or signs of UGI bleed. All patients were divided into two groups, group A (age < 60 years), and group B (age $\geqslant 60$ years). UGI endoscopy was performed using Olympus N19 Endoscope. Rockall scoring (RS) system and Glasgow Blatchford score (GBS) were used to predict the prognosis and re-bleeding.

\section{Results}

Of the total, group A included 150 (77.31\%) patients and group B 44 (22.69\%) patients. The most common presentation was hematemesis and melena in both groups, whilst isolated hematochezia was more common in group A (6.67\%, vs. $2.27 \%, \mathrm{p}>0.05)$. The main cause of bleeding was a variceal bleed in both groups, but it was significantly higher in group A patients $(p<0.05)$. Elderly patients had a significantly higher number of peptic ulcer and malignancy-related bleed $(\mathrm{p}<0.05)$. Group A patients had a significantly higher proportion of patients with tachycardia (45.33\%, vs. $27.27 \%$, p<0.05), shock ( $43.33 \%$ vs. $13.63 \%$, p $<0.05)$, pallor $(76.66 \%$ vs. $56.81 \%$, $\mathrm{p}<0.05)$, and blood transfusion requirement ( $64 \%$ vs. $45.45 \%$, $\mathrm{p}<0.05$ ) as compared to group B. Thirty days re-bleeding and mortality rate were similar in both the groups. RS in both groups was $5.02 \pm 2.12$ vs. $5.98 \pm 1.91, \mathrm{p}>0.05$. GBS was $11.65 \pm 4.61$ vs. $10.68 \pm 4.65$, $\mathrm{p}>0.05$. Mortality was significantly higher in patients with RS $\geqslant 6$ and GBS $\geqslant 10$.

Review began 02/10/2021 Review ended 02/15/2021 Published 02/23/2021

(c) Copyright 2021 Yadav et al. This is an open access article distributed under the terms of the Creative Commons Attribution License CC-BY 4.0., which permits unrestricted use, distribution, and reproduction in any medium, provided the original author and source are credited.

\section{Conclusion}

This study concluded variceal bleeding as a predominant cause of UGI bleed in both age groups, and it was significantly higher in younger. Interestingly, younger patients were more hemodynamically unstable, probably due to the presence of more severe anemia, shock, and hematochezia. The presence of multiple comorbidities in both the group kept the 30 days mortality and re-bleed rates similar.

Categories: Family/General Practice, Internal Medicine, Gastroenterology

Keywords: upper gastrointestinal bleeding, varices, co-morbidity, mortality, re-bleed

\section{Introduction}

Acute upper gastrointestinal (UGI) bleeding is one of the common life-threatening medical emergencies worldwide, having a mortality of around 2-10\% [1]. UGI bleeding includes bleeding from the esophagus, stomach, and duodenum up to the ligament of treitz. UGI bleed is common in the male population and the annual incidence ranges from 50 to $150 / 100,000$ population with increasing prevalence in aged people [2-4]. The mortality and morbidity because of UGI bleed is a major concern and mainly depends on patients' demographic profile, cause of bleed, and timely management of the same. Patients above the age of 60 years represent $35-45 \%$ of all patients presenting with UGI bleed [5-8]. Elderly patients have more chances of deterioration after UGI bleed due to multiple comorbidities, underlying preexisting diseases, or a history of chronic nonsteroidal anti-inflammatory drug (NSAID) or antiplatelet use. The usual presentation of UGI bleed is hematemesis and/or melena or hematochezia [9]. Endoscopic and medical 
management, including terlipressin, octreotide, and proton-pump inhibitors are the mainstay of treatment. Despite many recent advances in diagnostic and treatment modalities of UGI bleed, re-bleed and mortality rates are still high, the in-hospital mortality rate is high (13\%), and re-bleeding is common (15\%) $[3,10,11]$.

In India, the portal hypertension-related variceal bleed was found to be the most common cause of UGI bleed $[12,13]$. In contrast in another study from the Orisa state of India, the duodenal ulcer was found to be the most common [14]. We herein aimed to study the clinico-endoscopic profile and UGI bleeding outcomes in patients of age $<60$ years as compared to the older ones ( $\geqslant 60$ years).

\section{Materials And Methods}

This was a prospective observational study conducted in the Department of Medicine and Gastroenterology of Dr. S.N. Medical College, Jodhpur, India, from January 2015 to 2016 . The study was approved by the ethical committee of the College.

The inclusion criterion was patients aged $>12$ years with the presentation of symptoms or signs of UGI bleed who gave informed or written consent.

The exclusion criteria were patients who had bleeding due to road traffic accident, had contraindications for endoscopy, or who were unwilling to participate in the study.

All these patients were divided into two groups according to their age; group A - patients with age < 60 years, and group B with age $\geqslant 60$ years. Their detailed clinical history, demographic profile, and examination findings, including vital parameters were noted. All necessary lab investigations required for diagnosing the cause of UGI bleed and for co-morbidities were done. These included hemogram, renal function test, liver function tests, prothrombin time and international normalized ratio, blood grouping, ultra-sonography, chest X-ray, ECG, etc. Blood transfusion and other blood products were given when required. After the patient became hemodynamically stable, a UGI endoscopy was performed using Olympus N 19 Endoscope. Rockall scoring (RS) system and Glasgow Blatchford score (GBS) were used to predict the prognosis and rebleeding $[15,16]$. Parameters, i.e., age, initial heart rate, systolic blood pressure, melena or syncope, hemoglobin, blood urea nitrogen, coexistent hepatic disease, heart failure, or other significant comorbidities and endoscopic findings were noted for calculating RS and GBS.

\section{Statistical analysis}

Categorical variables were presented as frequencies or percentages and continuous variables as mean \pm SD. We used Fisher's exact and Chi-square test to compare and analyze categorical data, and the Student t-test for continuous variables. Values were considered significant if $\mathrm{p}<0.05$ ( $95 \%$ confidence interval). Data collected were managed on a Microsoft Excel sheet, analyzed using the latest version of Microsoft Office 2010 and using GraphPad QuickCalc online (GraphPad Software, San Diego, CA).

\section{Results}

From the total number of 194 patients with UGI bleeding presented, 150 patients (77.31\%) belonged to group A, and 44 (22.69\%) belonged to group B. Majority of patients in both groups were male (86.11\% vs. $75 \%$ ). The co-morbidities and demographic, clinical, and laboratory profiles of patients of both groups are depicted in Table 1 . The percentage of patients with co-morbidities like the previous history of liver disease, history of previous UGI bleed, and corrosive ingestion were higher among group A patients, whereas non-hepatic disease (i.e., cardiac, diabetes, hypertension, respiratory, malignancies diseases) and history of drug intake were higher among elderly patients (group B).

\begin{tabular}{|c|c|c|c|}
\hline Characteristics & Group A (age $<60$ years) & Group B (age $\geq 60$ years) & P-value \\
\hline Number of study patients (n) & 150 & 44 & \\
\hline Age (mean \pm SD years) & $39.23 \pm 10.96$ & $69.34 \pm 8.31$ & $\mathrm{P}<0.05$ \\
\hline Range (years) & $(13-58)$ & $(60-85)$ & \\
\hline Male/female (n/n) & $126 / 24$ & $33 / 11$ & $P>0.05$ \\
\hline \multicolumn{4}{|c|}{ Co-morbidities/diseases in past: $\mathrm{n}(\%)$} \\
\hline Liver disease & 103(68.67) & 20(45.45) & $\mathrm{P}<0.05$ \\
\hline Previous GI bleed & $57(38)$ & 13(29.54) & $P>0.05$ \\
\hline Diabetics mellitus & $06(04)$ & 12(27.27) & $\mathrm{P}<0.05$ \\
\hline Cardiac & $01(0.67)$ & 10(22.72) & $P<0.05$ \\
\hline
\end{tabular}




\section{Cureus}

$\begin{array}{llll}\text { Neurological } & 01(0.67) & 02(4.54) & \mathrm{P}>0.05 \\ \text { Renal disease } & 05(3.33) & 02(4.54) & \mathrm{P}>0.05 \\ \text { Hypertension } & 07(4.67) & 13(29.54) & \mathrm{P}<0.05 \\ \text { Respiratory } & 05(3.33) & 04(9.09) & \mathrm{P}>0.05 \\ \text { H/O corrosive in past } & 04(2.67) & 00(0) & \mathrm{P}>0.05 \\ \text { Drug treatment } & 27(18) & 21(47.73) & \mathrm{P}<0.05 \\ \text { AFI } & 21(13.33) & 4(9.09) & \mathrm{P}>0.05 \\ \text { Acute pancreatitis } & 01(0.67) & 00(0) & \mathrm{P}>0.05\end{array}$

Clinical presentation: $\mathrm{n}(\%)$

Hematemesis
Melana

96(64)

$110(73.33)$

29(65.9)

$P>0.05$

Hemetemesis+malena

57(38)

32(72.72)

$\mathrm{P}>0.05$

Hematochezia

10(6.67)

17(38.63)

$P>0.05$

1(2.27)

$\mathrm{P}>0.05$

Syncope+melena

$38(25.33)$

10(22.73)

$P>0.05$

Hemetemsis+syncope

27(18)

$5(11.36)$

$\mathrm{P}>0.05$

UAP

37(24.67)

15(34.09)

$P>0.05$

$\geq 3$ symptoms

35(23.33)

14(31.81)

$P>0.05$

Addiction: (n/\%)

Smoker

$45(30)$

7(15.9)

$P>0.05$

Alcoholic

No addiction

74(49.33)

10(22.7)

$\mathrm{P}<0.05$

70(46.67)

32(72.72)

$\mathrm{P}<0.05$

$\mathrm{SPO}_{2}($ mean $\pm \mathrm{SD})$

$95.72 \pm 5.47$

$95.16 \pm 4.98$

$P>0.05$

$\mathrm{SPO}_{2}<95 \%$ (n)

28

15

$\mathrm{P}<0.05$

Pulse rate $(\mathrm{bpm})(\mathrm{mean} \mathrm{SD})$

$94.8 \pm 12.26$

$90.14 \pm 12.43$

$\mathrm{P}<0.05$

Pulse rate $>100 \mathrm{bpm}(\mathrm{n} / \%)$

68(45.33)

12(27.27)

$\mathrm{P}<0.05$

Shock (n)

65(43.33)

6(13.63)

$\mathrm{P}<0.05$

115(76.66)

25(56.81)

$\mathrm{P}<0.05$

Hemoglobin $(\mathrm{g} / \mathrm{dL})(\mathrm{mean} \pm \mathrm{SD})$

$8.04 \pm 2.6$

$8.97 \pm 2.77$

$\mathrm{P}<0.05$

$1.76 \pm 1.04$

$1.51 \pm 0.45$

$P>0.05$

$26.33 \pm 18.08$

$32.76 \pm 19.77$

$\mathrm{P}<0.05$

$1.62 \pm 1.40$

$1.84 \pm 1.54$

$P>0.05$

\section{TABLE 1: Characteristics of study patients.}

$\mathrm{n}$ : number of patients, AFI: acute febrile illness, UAP: upper abdominal pain, $\mathrm{SpO}_{2}$ : saturation of oxygen, bpm: beats per minute, BUN: blood urea nitrogen. Shock is defined as mean arterial blood pressure of $<100 \mathrm{~mm} \mathrm{Hg}$ and tachycardia as pulse rate of $>100$ beats per minute.

The commonest presenting symptom of UGI bleed was melena and hematemesis in both groups. Out of 150 patients of group A, 110(73.33\%) had isolated melena, 96(64\%) had isolated hematemesis while 57(38\%) had both hematemesis and melena. In group B patients, isolated melena was seen in 32(72.72\%) patients, hematemesis in 29(65.9\%), and both hematemesis and melena in 17(38.63\%). Isolated hematochezia was more common in group A than in B [10(6.66\%) vs. $1(2.27 \%), \mathrm{p}>0.05]$. The proportion of patients with tachycardia was $47.22 \%(\mathrm{n}=68)$ and $27.27 \%(\mathrm{n}=12)$, that with shock was $43.33 \%(\mathrm{n}=65)$ and $13.63 \%(\mathrm{n}=6)$, pallor 


\section{Cureus}

was $76.67 \%(\mathrm{n}=115)$ and $56.81 \%(\mathrm{n}=25)$, and $\mathrm{SpO}_{2}<95$ was $18.66 \%(\mathrm{n}=28)$ and $34.09 \%(\mathrm{n}=15)$ in groups $\mathrm{A}$ and $\mathrm{B}$, respectively. P-value was $<0.05$ for all these parameters.

Of the total 150 patients of group A, 98(65.33\%) patients had variceal bleeding, and 52(34.67\%) patients had non-variceal bleeding. This proportion in group B was 20(45.45\%) and 24(54.55\%). Overall, the most common isolated cause of bleed was esophageal varices in both groups. Bleeding due to esophageal varices was significantly higher in group A as compared to group B [96(64\%) vs. 19(43.18\%), p<0.05]. The proportion of patients with gastric varices [17(11.33\%) vs. 4(9\%)] was similar between groups A and B. Bleeding from peptic ulcer, including gastric and duodenal ulcer was the significant cause of bleeding among group B patients [10(22.72\%)] as compared to group A patients [8(5.33\%)] $(\mathrm{p}<0.05)$. Upper GI malignancy-related UGI bleed was more common in group B, and the result was statistically significant (p-value $<0.05$; Table 2 ).

\begin{tabular}{|c|c|c|c|}
\hline Endoscopic profile: (n/\%) & Group A (age $<60$ years) & Group B (age $\geq 60$ years) & P-value \\
\hline Variceal- & $98(65.33)$ & $20(45.45)$ & $P<0.05$ \\
\hline EV & $96(64)$ & 19(43.18) & $\mathrm{P}<0.05$ \\
\hline GV & 17(11.33) & 4(9) & $P>0.05$ \\
\hline \multicolumn{4}{|l|}{ Nonvariceal } \\
\hline PU & $8(5.33)$ & 10(22.72) & $\mathrm{P}<0.05$ \\
\hline GU & $6(4)$ & $5(11.36)$ & $\mathrm{P}>0.05$ \\
\hline DU & $2(1.33)$ & $5(11.36)$ & $P>0.05$ \\
\hline MVT & $4(2.67)$ & $0(0)$ & $\mathrm{P}>0.05$ \\
\hline Malignancy & $5(3.33)$ & 6(13.63) & $\mathrm{P}<0.05$ \\
\hline GAVE & 23(15.33) & $2(4.5)$ & $P>0.05$ \\
\hline EMD & 19(12.67) & $10(22.72)$ & $P>0.05$ \\
\hline Polyp & $0(0)$ & $1(2.27)$ & $\mathrm{P}>0.05$ \\
\hline E ulcer & $1(0.67)$ & $0(0)$ & $\mathrm{P}>0.05$ \\
\hline No source located & $18(12)$ & $06(13.63)$ & $P>0.05$ \\
\hline
\end{tabular}

TABLE 2: Causes of acute upper gastrointestinal bleeding - endoscopic findings according to age n (\%).

EV: esophageal varices, GV: gastric varices, PU: peptic ulcer, GU: gastric ulcer, DU: duodenal ulcer, MVT: Mallory-Weis tear, GAVE: gastric antral vascular ectasia, EMD: esophageal mucosal disease, E ulcer: esophageal ulcer.

All patients of both groups were managed using terlipressin, proton pump inhibitors, and/or endotherapy. Surgical therapy was not required in any patients of variceal bleed. The requirement of blood transfusion was in $96(64 \%)$ patients of group A and 20(45.45\%) in group B ( $<<0.05)$

In our study, mortality was $9.33 \%(n=14)$ in group $A$ and $13.63 \%(n=6)$ in group $B$ (p-value $>0.05)$. Except for one death in the younger age group, all were due to variceal re-bleed. Whereas in the older group, two deaths were due to variceal bleed, the other two deaths were due to gastric ulcer re-bleed, one due to duodenal ulcer re-bleed, and one due to underlying co-morbidity in a case of a gastric bleed. Fifteen (10\%) patients from group A and 6(13.63\%) from group B developed re-bleeding in 30 days follow-up. The difference in RS in both groups was statistically not significant $(5.02 \pm 2.12,5.98 \pm 1.91 ; p>0.05)$. RS $\geqslant 6$ was present in $62(41.33 \%)$ patients of the younger age group; of them, 13 succumbed to death. Similarly, RS $\geqslant 6$ was seen in $23(52.27 \%)$ patients of the older age group and mortality occurred in four patients. Mean GBS was $11.65 \pm 4.61$ in group A and $10.68 \pm 4.65$ in group $B(p>0.05)$. GBS $\geqslant 10$ was found in $107(71.33 \%)$ patients of the younger age group, out of which there were 14 deaths. On the other hand, 24(54.54\%) patients of the older group had GBS $\geqslant 10$ and had mortality in five patients $(\mathrm{p}<0.05$; Table 3$)$. 


\begin{tabular}{|c|c|c|c|}
\hline Management & Group A (age <60 years) & Group B (age $\geq 60$ years) & p-Value \\
\hline Endoscopic treatment $(\mathrm{n} / \%)$ & $120(80)$ & $36(81.81)$ & $p>0.05$ \\
\hline Terlipression (n/\%) & $95(63.33)$ & $16(36.36)$ & $p<0.05$ \\
\hline Blood transfusion (n/\%) & $96(64)$ & 20(45.45) & $p<0.05$ \\
\hline Band ligation (n/\%) & $81(54)$ & $17(38.63)$ & $p>0.05$ \\
\hline Endotherapy successful (n/\%) & $84(56)$ & 17(38.63) & $p>0.05$ \\
\hline \multicolumn{4}{|l|}{ Outcome } \\
\hline RS (Mean \pm SD) & $5.02 \pm 2.12$ & $5.98 \pm 1.91$ & $p>0.05$ \\
\hline GBS (Mean \pm SD) & $11.65 \pm 4.61$ & $10.68 \pm 4.65$ & $p>0.05$ \\
\hline Re-bleed 30 days (n/\%) & 15(10) & 6(13.63) & $p>0.05$ \\
\hline Mortality 30 days (n/\%) & 14(9.33) & 6(13.63) & $p>0.05$ \\
\hline \multicolumn{4}{|l|}{$\mathrm{RS}>6$} \\
\hline Total number (n) & $62(p<0.05)$ & $29(p<0.05)$ & \\
\hline Mortality (n) & 13 & 4 & \\
\hline \multicolumn{4}{|l|}{ GBS>10 } \\
\hline Total number (n) & 107 & 24 & \\
\hline Mortality (n) & $14(p<0.05)$ & $5(p<0.05)$ & \\
\hline \multicolumn{4}{|l|}{ Mean duration of hospital stay } \\
\hline Days (mean $\pm S D$ ) & $5.22 \pm 2.5$ & $6.16 \pm 2.96$ & $p<0.05$ \\
\hline
\end{tabular}

\section{TABLE 3: Management and outcome of upper gastrointestinal bleeding in study patients.}

RS: Rockall score, GBS: Glasgow Blatchford score.

\section{Discussion}

Despite many recent advanced techniques in the field of gastroenterology to diagnose the cause of UGI bleed, UGI endoscopy is still the primary modality for the evaluation of UGI bleed. Endoscopy has a sensitivity of $92 \%$ and specificity up to $100 \%[17,18]$.

In our study, the majority ( $77.31 \%$ ) of patients were of $<60$ years age group and $22.69 \%$ of $\geqslant 60$ years age group. In another study from India, the prevalence of the older ( $\geqslant 60$ years) population was $33.15 \%$ in patients who presented with UGI bleed. Hematemesis and melena were the most common presenting symptoms. The prevalence of isolated hematochezia in our study was more common in the younger age group patients as compared to the older population (6.66\% vs. 2.27\%), which is studied by Saurabh et al. (1.9\% vs. 29\%) [19].

Saurabh et al. also found variceal bleeding as the most common cause and endoscopic finding of UGI bleed in both the groups, but in their study, the prevalence of variceal bleed was low as compare to our study. They also found gastric and duodenal ulcers as a predominant cause of bleeding in the elderly group [19].

We found tachycardia, shock, and blood transfusion (BT) requirement much more common in younger patients. This finding was contrary to Saurabh et al., in which postural hypotension $(29.3 \%$ vs. $14.9 \%$, $\mathrm{p}<0.01)$ and BT requirement $(20.2 \%$ vs. $10.1 \%$, p<0.01) significantly higher among the elderly group than in the non-elderly group [19]. More prevalence of tachycardia and shock in the younger age group can be explained by more number of younger patients with variceal bleed. Variceal bleed tends to cause profuse bleeding. More number of patients having isolated hematochezia in the younger group can contribute to severe anemia, as hematochezia is the passage of rapid and fresh bleeding per anum. Thirty days re-bleed (group A 10\%, group B 13.67\%) and mortality rates (group A 9.33\%, group B 13.63\%) were similar in both groups. Saurabh et al. also had similar re-bleeding rates in both groups but had the mortality rate is significantly higher in elderly patients compared to the non-elderly patients ( $10.32 \%$ vs. $1.94 \%$, p<0.01). They explained this by the presence of multiple co-morbidities and chronic drug intake in these patients [19]. The similar mortality rate in both the groups in our study was probably because of the presence of co-morbidities 
in both the groups. Younger age group patients had a much higher prevalence of the underlying liver disease, history of previous GI bleed, and history of corrosive injection, whereas the older population had a significantly higher number of patients suffering from non-hepatic disease, i.e., cardiac, diabetes, renal, chronic drug injection, hypertension. The mortality rates among patients aged over 60 years vary from $12 \%$ to $35 \%$, while the corresponding rate for patients younger than 60 years of age is $<10 \%[5,20]$.

Charatcharoenwitthaya et al. studied clinico-endoscopic diagnosis and outcome of UGI bleed between patients aged $\geqslant 65$ years compared with those aged $<65$ years and found peptic ulcer bleed as a predominant cause followed by varices and gastropathy. They noticed hemodynamic instability less in the elderly group, contrary to our study. They found a similar clinical course with regard to the utilization of endoscopic therapy, the requirement for transfusion, duration of hospital stay, need for surgery, rebleeding, and mortality between younger and elderly age group patients [21]. Theocharis et al. found peptic ulcers as the main cause of bleeding in patients aged more than 65 years. Co-morbidity, in-hospital complications, and deaths were more common in octogenarians and the severe co-morbidity was the main adverse factor for clinical outcome and mortality [22].

The less prevalence of peptic ulcer disease in our study may be due to lesser use of NSAIDs, and eradication of Helicobacter pylori infection. A literature search showed re-bleeding rate varies widely and ranges from $20 \%$ to $30 \%$ and is affected by multiple factors. This study shows that the trend of UGI bleeding in western Rajasthan is different from the developed countries as UK Audit 2007 has reported only $11 \%$ bleeding varices and Snaders et al. have reported only $4.4 \%[23,24]$. The majority of younger age group patients who died had re-bleeding and had underlying liver disease and a history of previous GI bleed. It appears that co-morbid illness predisposes for re-bleed.

\section{Conclusions}

In conclusion, we found that nearly $22 \%$ of patients who presented with UGI bleed belong to the age group $\geqslant 60$ years. Clinical presentation of UGI bleed in both age groups was almost similar with variceal bleeding being the most common cause. Hemodynamic instability was more in the younger age group probably due to more number of younger patients with variceal bleed with more severe anemia, shock, and hematochezia. The presence of multiple co-morbidities in both groups kept 30 days mortality and re-bleed rates similar. Hence, it is a clinical challenge to deal with younger as well as elderly patients for proper management and prevention of underlying diseases, comorbidities, and risk factors to prevent UGI bleed.

\section{Additional Information \\ Disclosures}

Human subjects: Consent was obtained or waived by all participants in this study. Ethical Committee of the Dr. S.N. Medical College, Jodhpur, India issued approval NA. THIS study was approved by the ethical committee of the medical college. Data were collected after obtaining approval from the ethical committee of the Medical College. Animal subjects: All authors have confirmed that this study did not involve animal subjects or tissue. Conflicts of interest: In compliance with the ICMJE uniform disclosure form, all authors declare the following: Payment/services info: All authors have declared that no financial support was received from any organization for the submitted work. Financial relationships: All authors have declared that they have no financial relationships at present or within the previous three years with any organizations that might have an interest in the submitted work. Other relationships: All authors have declared that there are no other relationships or activities that could appear to have influenced the submitted work.

\section{References}

1. Stanley AJ, Laine L: Management of acute upper gastrointestinal bleeding . BMJ. 2019, 364:1536 10.1136/bmj.1536

2. Longstreth GF: Epidemiology of hospitalization for acute upper gastrointestinal hemorrhage: a populationbased study. Am J Gastroenterol. 1995, 90:206-10.

3. van Leerdam ME, Vreeburg EM, Rauws EA, et al.: Acute upper GI bleeding: did anything change? Time trend analysis of incidence and outcome of acute upper GI bleeding between 1993/1994 and 2000. Am J Gastroenterol. 2003, 98:1494-9. 10.1111/j.1572-0241.2003.07517.x

4. Thomopoulos KC, Vagenas KA, Vagianos CE, Margaritis VG, Blikas AP, Katsakoulis EC, Nikolopoulou VN: Changes in aetiology and clinical outcome of acute upper gastrointestinal bleeding during the last 15 years . Eur J Gastroenterol Hepatol. 2004, 16:82. 10.1097/00042737-200402000-00009

5. Rockall TA, Logan RF, Devlin HB, Northfield TC: Incidence of and mortality from acute upper gastrointestinal haemorrhage in the United Kingdom. Steering Committee and members of the National Audit of Acute Upper Gastrointestinal Haemorrhage. BMJ. 1995, 311:222-6. 10.1136/bmj.311.6999.222

6. Cooper BT, Weston CF, Neumann CS: Acute upper gastrointestinal haemorrhage in patients aged 80 years or more. Q J Med. 1988, 68:765-74.

7. Hernandez-Diaz S, Rodriguez LA: Incidence of serious upper gastrointestinal bleeding/perforation in the general population: review of epidemiologic studies. J Clin Epidemiol. 2002, 55:157-63. 10.1016/s08954356(01)00461-9

8. Higham J, Kang JY, Majeed A: Recent trends in admissions and mortality due to peptic ulcer in England: 
increasing frequency of haemorrhage among older subjects. Gut. 2002, 50:460-4. 10.1136/gut.50.4.460

9. Jung K, Moon W: Role of endoscopy in acute gastrointestinal bleeding in real clinical practice: an evidencebased review. World J Gastrointest Endosc. 2019, 11:68-83. 10.4253/wjge.v11.i2.68

10. Barkun AN, Bardou M, Kuipers EJ, et al.: International consensus recommendations on the management of patients with nonvariceal upper gastrointestinal bleeding. Ann Intern Med. 2010, 152:101-13. 10.7326/00034819-152-2-201001190-00009

11. Wilkins T, Khan N, Nabh A, Schade RR: Diagnosis and management of upper gastrointestinal bleeding. Am Fam Physician. 2012, 85:469-76.

12. Banerjee A, Bishnu S, Dhali GK: Acute upper gastrointestinal bleed: an audit of the causes and outcomes from a tertiary care center in eastern India. Indian J Gastroenterol. 2019, 38:190-202. 10.1007/s12664-01800930-7

13. Mahajan P, Chandail VS: Etiological and endoscopic profile of middle aged and elderly patients with upper gastrointestinal bleeding in a Tertiary Care Hospital in North India: a retrospective analysis. J Mid-Life Health. 2017, 8:137-41. 10.4103/jmh.JMH_86_17

14. Singh SP, Panigrahi MK: Spectrum of upper gastrointestinal hemorrhage in coastal Odisha . Trop Gastroenterol. 2013, 34:14-7. 10.7869/tg.2012.85

15. Rockall TA, Logan RF, Devlin HB, Northfield TC: Risk assessment after acute upper gastrointestinal haemorrhage. Gut. 1996, 38:316-21. 10.1136/gut.38.3.316

16. Blatchford O, Murray W, Blatchford M: A risk score to predict need for treatment for upper gastrointestinal haemorrhage. Lancet. 2000, 356:1318-21. 10.1016/S0140-6736(00)02816-6

17. Dooley CP, Larson AW, Stace NH, et al.: Double-contrast barium meal and upper gastrointestinal endoscopy. A comparative study. Ann Intern Med. 1984, 101:538-45. 10.7326/0003-4819-101-4-538

18. Jaskolka JD, Binkhamis S, Prabhudesai V, Chawla TP: Acute gastrointestinal hemorrhage: radiologic diagnosis and management. Can Assoc Radiol J. 2013, 64:90-100. 10.1016/j.carj.2012.08.001

19. Sourabh S, Sharma N, Sharma R, et al.: Clinical profile, severity and outcome of acute upper gastrointestinal bleeding in elderly patients compared to non-elderly patients: a prospective observational study. J Assoc Physicians India. 2019, 67:30-2.

20. Christensen S, Riis A, Norgaard M, Sorensen HT, Thomsen RW: Short-term mortality after perforated or bleeding peptic ulcer among elderly patients: a population-based cohort study. BMC Geriatr. 2007, 7:8. 10.1186/1471-2318-7-8

21. Charatcharoenwitthaya P, Pausawasdi N, Laosanguaneak N, Bubthamala J, Tanwandee T, Leelakusolvong S: Characteristics and outcomes of acute upper gastrointestinal bleeding after therapeutic endoscopy in the elderly. World J Gastroenterol. 2011, 17:3724-32. 10.3748/wjg.v17.i32.3724

22. Theocharis GJ, Arvaniti V, Assimakopoulos SF, Thomopoulos KC, Xourgias V, Mylonakou I, Nikolopoulou $\mathrm{VN}$ : Acute upper gastrointestinal bleeding in octogenarians: clinical outcome and factors related to mortality. World J Gastroenterol. 2008, 14:4047-53. 10.3748/wjg.14.4047

23. Hearnshaw SA, Logan RF, Lowe D, Travis SP, Murphy MF, Palmer KR: Acute upper gastrointestinal bleeding in the UK: patient characteristics, diagnoses and outcomes in the 2007 UK audit. Gut. 2011, 60:1327-35. 10.1136/gut.2010.228437

24. Sanders DS, Carter MJ, Goodchap RJ, Cross SS, Gleeson DC, Lobo AJ: Prospective validation of the Rockall Scoring system for upper GI haemorrhages in subgroup of patients with varices and peptic ulcers. Am J Gastroenterol. 2002, 97:630-35. 10.1111/j.1572-0241.2002.05541.x 